\title{
ENTREVISTA COM KAROL CORDEIRO: UMA HISTÓRIA DE AMOR E LUTA PELA INCLUSÃO ATRAVÉS DA ARTE
}

\section{DOI: $\underline{\text { http://dx.doi.org/10.5965/1984317816012020254 }}$}

Karolina Cordeiro é geógrafa de formação, doula por missão e escritora por paixão. Mãe da Ana Júlia, do Pedro e da Giovana. Fundadora do Projeto Angel Hair (cultura, arte, educação e inclusão), que leva apresentações itinerantes em escolas públicas de dança inclusiva e palestras em várias cidades do Brasil. O Projeto nasceu depois que seu filho Pedro desenvolveu uma síndrome rara chamada Aicardi Goutieres. Ativista pelos direitos humanos. Facilitadora em desenvolvimento humano no Movimente Ateliê. Palestrante e colunista da revista Cult, articulista da Revista Reação (revista nacional de reabilitação) e colunista da revista Triângulo Esporte. Membro da Comissão em Defesa da Pessoa com Deficiência da OAB Minas, Diretora de Operações da AGS Síndromes da América do Sul. Corredora da Angel Hair Team. Cofundadora do Projeto Muda do Afeto (cartilha e livros sobre a pessoa com deficiência). Uma mulher e mãe que transforma a experiência de ter um filho com deficiência em aprendizado e oportunidade de criar relações significativas e importantes para um mundo melhor.

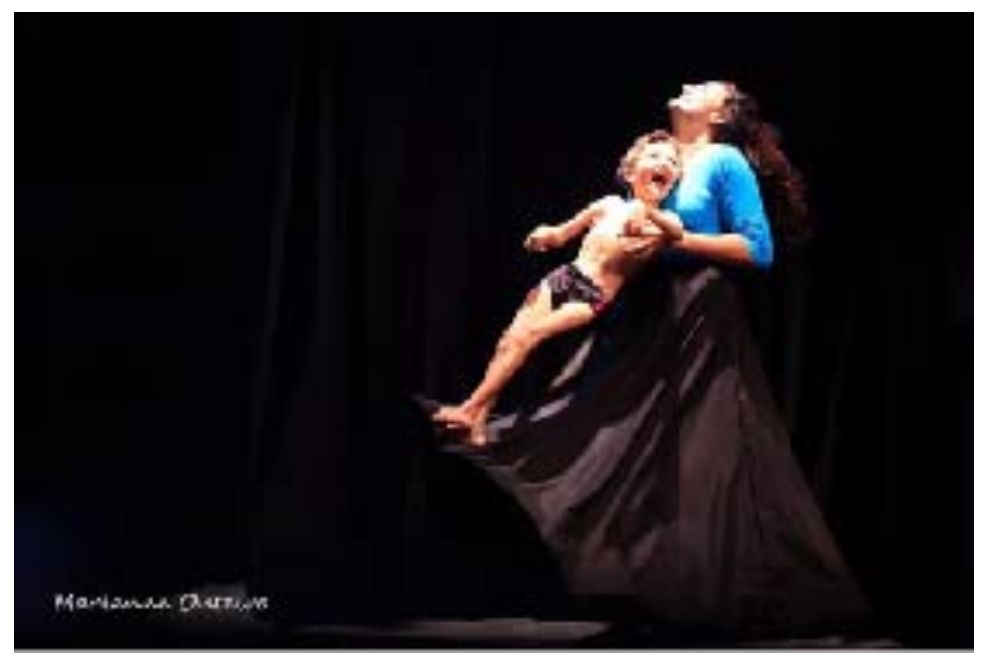

Figura 1 - Karol e Pedro em cena. Fonte: imagem cedida por Karol Cordeiro.

\section{REAl: Karol, você poderia nos falar um pouco como surgiu o Projeto Angel Hair?}

Karol: É um projeto que nasceu no mesmo instante que descobri que meu filho possuía uma síndrome rara, altamente limitadora e com pouca expectativa de vida. E a vontade de fazê-lo feliz todos os dias. Mas, existem muitas barreiras arquitetônicas e humanas que impedem 
as pessoas com deficiência de exercerem todo potencial humano, independente de sua forma física. Através das minhas vivências diárias, dores e pequenas vitórias pessoais, surge este projeto que tem por finalidade a humanização entre as relações das pessoas com deficiência. Porque quando o portão da minha casa se abre, abre-se um mundo de oportunidades para Pedroca1 se sentir vivo e, enquanto ele abrir os olhos, prometi a ele que seus dias valeriam a pena. Mas a história do deficiente no Brasil é de luta, preconceitos e pouquíssima informação. Penso que melhorando o mundo que nos cerca, o universo devolveria para meu filho toda sensação de estar neste mundo por um motivo forte; se sentir vivo, não só passar os dias. E o porquê do nome Angel Hair? Porque quando fomos fazer o exame [fora do país] para confirmar esta síndrome terrível, as enfermeiras tirando o sangue dele (momento que mudaria toda a nossa história), falavam "Oh, angel hair!", devido ao seus cabelos cacheados e loirinhos. Retornando ao Brasil, fomos viver. Na nossa primeira corrida, eu disse: "Filho, toda equipe tem um nome. Poderia ser 'Angel Hair', para nós nos lembrarmos, lembrarmos que notícias ruins existem, mas que podemos transformar lágrimas em suor. Nascia o Angel Hair e depois o Projeto Angel Hair, com cartilhas, palestras, dança e uma enorme vontade de levar informação sobre o universo da pessoa com deficiência. Luta e amor.
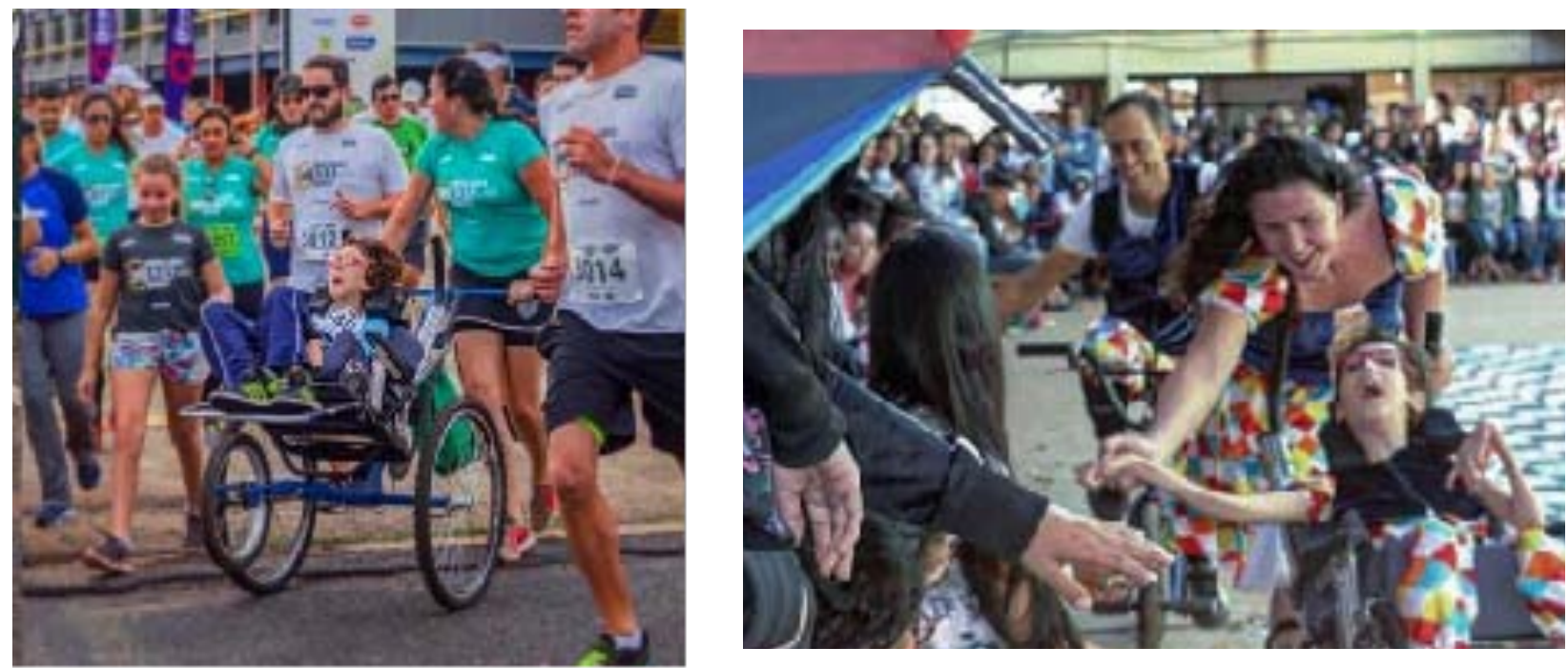

Figura 2: À esquerda, Karol e Pedro participando de corrida. À direita, Karol e Pedro em uma das apresentações de dança em escolas. Fonte: imagem cedida por Karol Cordeiro.

REAl: Vemos que o Projeto Angel Hair tem circulado em escolas, festivais e outros espaços públicos e educativos. Como você percebe a recepção do projeto nesses

\footnotetext{
${ }^{1}$ Apelido carinhoso do seu filho Pedro.
} 
espaços? Qual o principal objetivo do projeto ao levar esse debate acerca da arte e inclusão para as escolas?

Karol: Acredito na arte como transformadora de olhares e nas escolas temos a oportunidade de levar de forma genuína, porque a diferença pode encantar. A aceitação do projeto é bastante ampla. Acontece a dança, contação de histórias do livros e oficinas para os professores e educadores, sugerindo ferramentas que levem desde os alunos, professores e educadores até quem trabalha na secretaria e limpeza, a importância do sentir a deficiência. Foi um caminho muito bonito que escolhi ao transformar a dor em amor. Que todos na escola possam receber alunos com deficiência de forma sincera , leve e amorosa!

REAl: Nessa vida de tantos fazeres (mãe, doula, corredora, geógrafa, escritora), quando e como a dança entrou na sua vida? E como foi apresentar a dança ao Pedro e torná-lo parceiro nas apresentações?

Karol: Sempre imaginei como seria feliz com meu filho. E a dança veio da escolha da aceitação de seu corpo e como esse corpo poderia brincar com as possibilidades. Conheci vários livros da Maria Fux, uma argentina que desenvolve a dança através das emoções. Senti que ali iríamos nos divertir. Hoje apresentamos em escolas, empresas, instituições, festivais nacionais e internacionais.

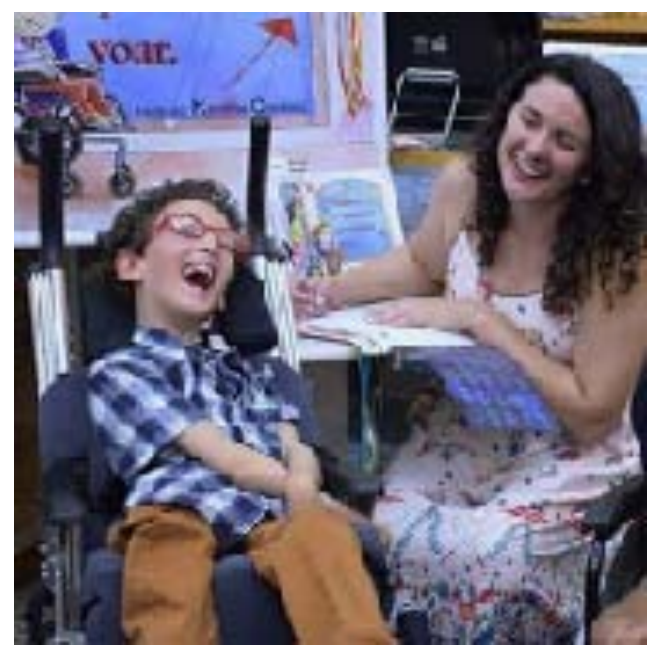

Figura 3: Karol e Pedro no lançamento do livro. Fonte: imagem cedida por Karol Cordeiro.

REAl: Karol, você poderia nos falar um pouco sobre a ideia do livro "Pedroca, 0 Menino que Sabia Voar"? Quando/ como surgiu essa proposta e como tem sido a circulação do livro?

Karol: O maior desafio e também o maior medo era como seria a vida escolar do meu filho Pedro. Quando vi a espontaneidade das crianças querendo saber como ele se comunica, se 
ele "entendia" as coisas e se era feliz, surgiu em mim uma alegria em ver num livro infantil a ponte para alcançar o coração dessas crianças. De forma lúdica, demonstrar que é legal ter um amigo especial e que ser diferente é normal. O livro foi bem aceito, sendo um sucesso o lançamento. Foi adotado em escolas públicas e privadas e distribuído pelo projeto Angel Hair através de leis de incentivo à cultura. O livro transforma o estigma da criança com deficiência grave de coitadinha e leva para o lugar de super herói, cheios de mistérios e descobertas.

REAl: Num âmbito mais pessoal, como mãe, qual você considera o(s) principal(is) desafio(s) para a inclusão em nossa sociedade?

Karol: A falta de empatia e humanização. Quando percebi que a acessibilidade não era somente uma rampa mas, sim, acessibilidade atitudinal - pois escolas, comércio e famílias tendem a querer criar bolhas para educar os filhos. O maior desafio é quebrar paradigmas, que a deficiência está no olhar de quem vê e não na limitação de uma pessoa.

REAl: É inspirador perceber o quanto você transformou um desafio em potência criadora e transformou a sua vida e a do Pedroca. $O$ que você gostaria/poderia dizer para nossas/os leitoras/es que se encontram em situação similar? E mais, o que você diria para as/os professoras/es e pesquisadoras/es dessa área?

Karol: Tenham um olhar mais demorado. Na ânsia do politicamente correto, de qual termo correto usar, como lidar com a pessoa com deficiência, que eles possam somente sentir. Esquecer a cartilha que insistimos em achar que o certo é o que nos ensinaram desde sempre. Cada dia é um dia. O mundo vai tratar seu filho da forma que você o trata em casa; a educação inclusiva é construção dos dois lados. Se permitir curar as nossas feridas internas para poder olhar a pessoa com deficiência de igual pra igual.

REAl- Karol, há algo mais que você gostaria de falar sobre? Fique a vontade para acrescentar qualquer outra informação que considere relevante e não tenhamos abordado aqui.

Karol: Que as famílias, os professores, a sociedade e a população não tenham medo de viver a diversidade humana; que se abram para viver a riqueza de se pertencer e deixar o outro sentir a autonomia da dignidade, e que seja valorizada a vida em cada respiração. 


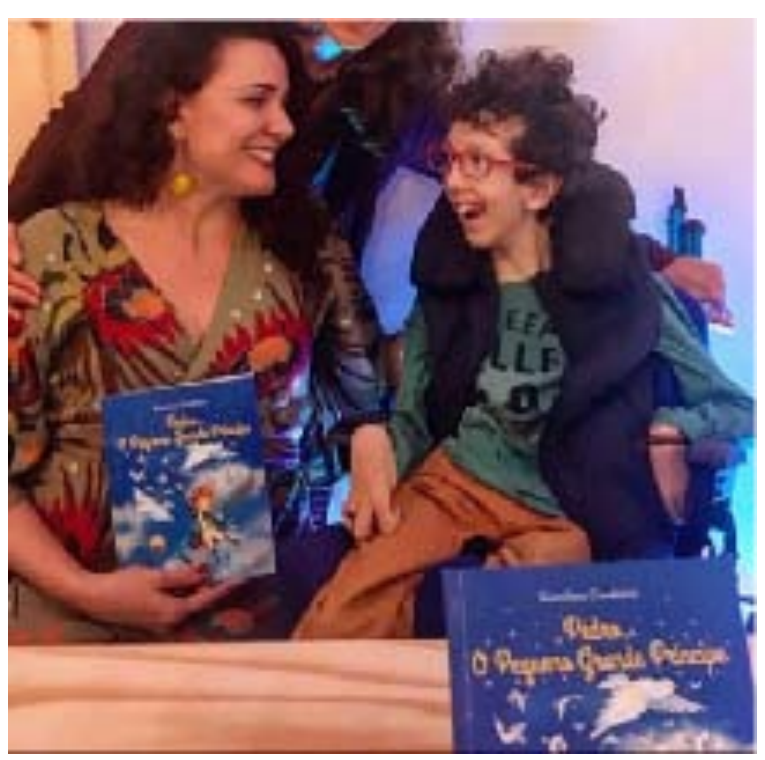

Figura 4: Karol e Pedro no lançamento do seu segundo livro "Pedro: o Pequeno Grande Príncipe". Fonte: imagem cedida por Karol Cordeiro.

Mais informações sobre o trabalho de Karol e Pedro Cordeiro podem ser encontradas em:

- Segundo livro sobre Pedroca está na Fliaraxá 2019: https:// diariodeuberlandia.com.br/noticia/21516/segundo-livro-sobre-pedroca-esta-nafliaraxa-2019

- Karolina corre maratonas com o filho tetraplégico: https://globoplay.globo.com/v/ $\underline{5449798 /}$

- Garoto com doença rara corre em MG guiado pela mãe em cadeira adaptada: https:// m.folha.uol.com.br/cotidiano/2017/12/1946276-garoto-com-doenca-rara-corre-emmg-guiado-pela-mae-em-cadeira-adaptada.shtml

- Karolina Cordeiro e seu filho Pedro: http://pernaspraquetequero.org/a-inspiracao/

- 'Prometi fazê-lo feliz enquanto viver', diz mãe de criança com doença rara: http:// g1.globo.com/minas-gerais/triangulo-mineiro/noticia/2014/02/prometi-faze-lo-felizenquanto-viver-diz-mae-de-crianca-com-doenca-rara.html

- Conheça a mãe que transformou adversidade em aventura: https:// boasnovasmg.com.br/2018/05/11/karolina-cordeiro-adversidade-aventura/

- "A vida que você escolheu": https://www.youtube.com/watch?v=Zpu0el5Y2o\&feature=youtu.be

\section{Entrevista concedida a Equipe Editorial da Revista Educação, Artes e Inclusão em Dezembro/2019.}

